\title{
Explicit Teaching and Incidental Learning of Vocabulary: Where Is the Pendulum Swinging to?
}

\author{
Faisal Al-Homoud ${ }^{1}$ \\ ${ }^{1}$ Department of English, College of Science and Humanities at Howtat Sudair, Majmaah University, Saudi \\ Arabia \\ Correspondence: Faisal Al-Homoud, Department of English, College of Science and Humanities at Howtat \\ Sudair, Majmaah University, Saudi Arabia. E-mail: f.alhomoud@mu.edu.sa
}

Received: August 22, 2019 Accepted: November 4, 2019 Online Published: November 24, 2019

doi:10.5539/ijel.v9n6p445 URL: https://doi.org/10.5539/ijel.v9n6p445

\begin{abstract}
The research at hand compared two conditions of L2 vocabulary exposures, i.e. incidental exposure and a mixture of incidental and explicit exposures to words. Forty-five female participants, majoring in English at Al-Imam Mohammad Ibn-Saud Islamic University, Saudi Arabia participated in this research. They were divided into two groups: Reading Only (RO) and Reading Extra (RE). In the RO group, the target words were exposed only through a reading passage that they read twice, while the same target words for the RE group were inserted in the same reading passage, then explained directly by the teacher. Three levels of vocabulary knowledge (form recall, meaning recall, and meaning recognition) were assessed. The results showed that both conditions cater for vocabulary learning, however the RE group had significantly outperformed their RO counterparts. Moreover, the results showed that vocabulary learning in this study followed the general tendency starting from a receptive level to a productive level.
\end{abstract}

Keywords: vocabulary knowledge, vocabulary learning, explicit teaching, incidental learning, attrition, retention

\section{Background}

Vocabulary knowledge has been assumed to be a vital part and parcel of language learning Pellicer-Sánchez (2017). However, gaining vocabulary knowledge is neither simple nor straightforward. Therefore, researchers interested in vocabulary learning have proposed two main approaches: incidental (i.e. indirect) learning, and explicit (i.e., direct) teaching of vocabulary. Moreover, it is assumed that L2 learners need to know a large number of words in order for them to be able to communicate orally in English (6,000-7,000-word families) and around 8,000-9,000-word families to be good at written communication (Nation, 2006). Therefore, Sánchez and Schmitt (2010) deem that it is difficult for teachers to cover this large number of word families for both genres in their teaching sessions. Hence, they believe that incidental learning is an appropriate solution for this problem. Furthermore, despite the smaller amounts of vocabulary gains from incidental learning (from reading and listening) in the L2, Waring and Nation (2004) believe that most of L2 learners learn their vocabulary through comprehensible input.

On the other hand, many researchers advocate that explicit teaching of vocabulary bears greater effect on L2 learners' vocabulary knowledge, especially if it is preceded by incidental exposures to that vocabulary (e.g., Nation, 2001; Zimmerman, 1997; Paribakht \& Wesche, 1997; Sonbul \& Schimtt, 2010). Sánchez and Schmitt (2010) assert that the most common 2,000-3,000-word families lend themselves to explicit teaching. Furthermore, Nation and Newton (1997) believe that high-frequency words deserve direct attention by teachers. Overall, it seems that explicit instruction is more effective than incidental learning in encouraging vocabulary learning.

Yet, research has not been conclusive on the mode of introducing new words to L2 learners. Hence, the current research is embarked on to compare the effect(s) of these two approaches in a classroom setting, and to tap the knowledge of new vocabulary at three different levels: form recall, meaning recall, and meaning recognition. Schmitt (2019) suggests using meaning recall formats for receptive tests and form recall for productive tests. This type of research is not so common (Sonbul \& Schmitt, 2010). Furthermore, this kind of research is scarce in the Saudi context, where research is highly needed to guide materials writers and teachers alike. In addition, Nation (2001) indicates that EFL contexts usually do not provide rich input for L2 learners to optimize their 
vocabulary learning; therefore, he advocates adding activities that provide explicit exposure to new vocabulary.

Besides, Snobul and Schmitt (2010) reached some strong results that contradict some common beliefs and practices in the field. Schmitt (2010) believes that researchers should be encouraged to replicate studies that were conducted once with strong results, as such studies have heretofore been cited many times without the results being submitted to further critical scrutiny. Schmitt also believes that replications would either confirm or refute such results, thus opening up new avenues for researchers. Therefore, the current study is a response to that call and is carried out to answer the following two research questions:

1) Is explicit teaching (the RE group) more effective than incidental learning (the RO group)?

2) To what degree do the incidental learning and explicit teaching input conditions facilitate vocabulary acquisition at the three levels of mastery of the form-meaning link (form recall, meaning recall, and meaning recognition)?

\section{Review of the Literature}

It is becoming apparent that vocabulary knowledge is one of the most significant factors affecting reading comprehension (Krashen, 1993; Aebersold \& Field, 1997; Grabe \& Stoller, 2002; Day \& Bamford, 1998; Qian, 1999; Schmitt, 2000; Nation, 2001; Al-Nujaidi, 2003; Mushait, 2003) as well as listening/watching comprehension (Rodgers, 2013; Webb \& Rodgers, 2013; Peters \& Webb, 2018), . Indeed, vocabulary knowledge and reading comprehension are highly interdependent: an increase in either will influence the other (Nation, 2001). Therefore, reading is seen as an important catalyst for increasing L2 learners' vocabulary repertoire (Nation \& Meara, 2002).

Nevertheless, learning vocabulary from reading usually requires a paramount time, and L2 learners seem to have a limited amount of time (Carter \& McCarthy, 1988). L2 learners need to have a habit of reading frequently and for sustained periods of time. Furthermore, L2 reading is usually prone to erroneous guessing (Bensoussan \& Laufer, 1984; Laufer \& Sim, 1985), and fuzziness in word meaning(s). More seriously, beginning L2 learners may have both difficulty and frustration when applying guessing skills (Sokmen, 1997). Indeed, L2 learners are much less effective in using context than L1 native speakers (Nagy, 1997). In addition, incidental learning is inclined to long-term retention (Rott, 1999; Sokmen, 1997; Waring \& Takaki, 2003). In a clearer voice, Paribakht and Wesche (1997) state that notwithstanding the obvious role of reading in vocabulary acquisition, both research and experience clearly show that the development is slow, often erroneous, and apparently random. They also stated that outcomes of such supporting research greatly vary for different learners, word types, and contexts.

On the other hand, other researchers have raised serious issues against explicit teaching. First, L2 learners are faced with a sheer volume of words. Furthermore, a word usually entails different aspects that need to be learned, e.g. meaning, form, sound, and register (Nagy, 1997). Second, explicit teaching, unlike incidental learning from reading, needs a great deal of effort and planning on the teacher's side, as well as the classroom time (Nation, 2001). Third, Huckin and Coady (1999) believe that incidental learning is usually contextualized, a feature that explicit teaching lacks in most cases. Fourth, incidental learning from reading entails learning different aspects of the language, not only vocabulary. Nation (2001) and Nagy (1997) believe that the number of words L2 learners need to learn during their learning process is far greater than being introduced in classroom encounters. Milton and Meara (1995) estimate that advanced L2 learners may be able to learn 2500 words per year. This large number of words cannot be covered in most, if not all, L2 classroom settings. Discouragingly, Nation (2015) believes that less than $50 \%$ of what is introduced in direct teaching of vocabulary is learned as a great deal of research on deliberate learning has revealed.

In conclusion, incidental vocabulary learning and deliberate vocabulary teaching are, and should be looked at as, complementary activities that each one augments the learning outcomes of the other (Nation, 2001). Therefore, these two approaches should not be seen as competitors or contradicting each other, rather, they should be seen as two sides of a coin. Each approach has its own pros and cons depending on the objectives of the L2 learners, teachers, or course.

In addition, Nation (2015) deems that explicit teaching helps in highlighting new vocabulary and reinforcing incidental learning. For instance, the most frequent words should have a direct attention, while low-frequency vocabulary can be left to implicit learning from reading and listening. In fact, a great deal of research supports the benefits of vocabulary gains from extensive reading (and listening), especially in poor-input settings (e.g., Alahirsh, 2014; Al-Homoud \& Schmitt, 2009; Alsaif \& Masrai, 2019). On the single word level, explicit teaching may be better for encountering the word and knowing its basic features. For more detailed or deeper 
aspects of the word, incidental learning can play a greater role through wide exposures to extensive input. Sokmen (1997) also contends that the direction has oscillated from direct teaching of vocabulary (the grammar translation method) to incidental (the communicative approach). Recently, Sokmen states, the pendulum has swung back to the middle: both deliberate and incidental learning.

The differences between these two approaches should be seen as a continuum, with intentional vocabulary teaching at one end, and incidental vocabulary learning at the other. For some learners, especially beginners, intentional vocabulary learning may be a must, especially, the most common words. For higher learners, however, deliberate teaching may be a waste of time, thus, the teaching of vocabulary learning strategies should be given priority. Furthermore, vocabulary acquisition is, and should be seen as, an accumulative process, where every encounter with the word adds an element to the previous knowledge of that acquisition. Moreover, taking individual learning styles into consideration, both approaches can cater for a good range of learning styles. In other words, certain word knowledge features are more salient when introduced explicitly (e.g., form, meaning, sound), while others are better noticed when encountered in a reading/listening context (e.g., definitions, collocations). In addition, certain aspects of word knowledge require different specifications. For instance, Schmitt (2000) believes that register constraints and collocational behavior may require a longer time to be acquired as they require a sheer volume of encounters with words.

\section{Methodology}

\subsection{Participants}

Forty-five female, university students took part in this study. They were majoring in English at level two at the College of Languages and Translation at Al-Imam Mohammad Ibn-Saud Islamic University in Riyadh, KSA. Their ages ranged between 18 and 20 years. The participants received exposure to English as a school subject at the age of 12. They were divided into two groups: A control group and an experimental group. The control group ( $n$ 21) was the Reading Only (henceforth, RO) group, where the target words were exposed only through a reading passage which they read twice. The experimental group $(n 24)$ was the Reading Extra (henceforth, RE) group where the target words were inserted in a reading passage, then explained directly by the teacher. There were 24 participants in this group. Hypothetically, Sonbul and Schmitt's (2010) participants and the participants in the current replication share similar characteristics in terms of culture, age, gender, number of years of English learning, as well as their university level.

\subsection{Materials}

The reading passage was selected from www.pearsonlongman.com (Note 1): It's All Clear Now by Jean Lawler (Appendix A). It was a 524-word extract. However, slight changes were made to the text to ensure that the target words occurred only once. Fifteen unknown words from the passage were chosen to be the target words (Appendix B). These 15 items were then added to another list of 17 unknown words in order to distract the participants' attention to the target items in the pre-test. The target words were the same for all groups (this is one of the major differences from Sonbul and Schmitt's study; both groups were equivalent in all aspects except for the type of exposure). In order to evaluate the suitability of the passage to the targeted participants in terms of the length of the passage, its linguistic level, and the expected reading time, the passage was piloted on 8 participants similar to those of the current study, and some necessary changes were made accordingly. Furthermore, the passage was given to three female professors teaching at level two then and agreed that the passage is suitable for the participants' proficiency level.

\subsection{Measurement Instruments}

Three levels of vocabulary knowledge (form recall, meaning recall, and meaning recognition) were measured for no prior knowledge of the target words using three tests that were developed (completion, L1 translation, and multiple choice, respectively) to measure the 15 target items.

First, a completion (fill-in-the-blanks) test was developed to assess form recall. Participants were provided with a brief meaning, in addition to the first-half letters of each target word, and were asked to complete the form. For example:

- When something gets (fuz ), it becomes unclear.

Second, meaning recall was measured by using an L1 translation:

$$
\text { English Words }
$$

Arabic Translation

1) Fuzzy

Finally, meaning recognition was gauged by using multiple-choice items (hereafter MC). Each item consisted 
of five options: the correct answer, three distracters, and one 'I do not know' option to minimize guessing.
1) fuzzy
a. scary
b. noisy
c. unclear
d. very cold
e. I do not know

As for the validity of the three tests, the three professors consulted earlier made some invaluable comments concerning the validity criterion. One of them suggested adding the option "I don't know" in the meaning recognition test as it is important for the participants not to make some wild guesses if they do not know the right answer. Other important comments concerned changing some item words in the MCQ test as they were either so clear, not matching the part speech of the target word, or difficult for the participants. Furthermore, the professors recommended that certain sentences in the form-recall test must be replaced by clearer substitutions as some of them were very long and disproportionate with other sentences. Necessary changes were taken into consideration in the final versions of the tests.

After mending some items of the form recall and meaning recognition tests and piloting the tests on 8 participants, reliability checks were run. Cronbach's alpha reliability coefficients were as follows:

\section{Reliability results}

\section{Test}

Form recall

Meaning recognition

Meaning recall

\section{Cronbach's alpha}

.768

.807

.695

\subsection{Procedure}

The current investigation adopted a quasi-experimental design in which the participants were classified into two groups: (a) an experimental group and (b) a control group. To assess their prior knowledge of the target words, the participants did not sit for a translation test a week before the experiment, as had occurred in the original study; rather they took it immediately before the experiment in order to minimize any possible learning from any exposures other than the test passage. As stated earlier, the 15 target words were intermixed with 12 non-target, unknown words in order to divert the participants' attention from the target items in the pre-test. The results of the pre-test revealed that the participants of both groups had zero knowledge of the target items before taking part in the experiment. The 12 non-target words were not inserted in any post-test as they were of no benefit to the study. So, all post-tests included only 15 items each.

The teacher (Note 2) did not allow any discussions about the passage during the class time in order to avoid any extra exposure to the target items. Moreover, the participants were not informed about any forthcoming tests. Copies of the passage were circulated, and learners were requested to read it silently for 10 minutes. Reading comprehension was not assessed, as this may have led to extra and uncontrolled exposure to the words. After the reading session, the 27 (target and non-target) words were explicitly explained to the RE group. The manner of presenting the words was different from the original study. In this study the teacher gave the L1 meaning for each word via PowerPoint slides, timing the presentation for 10 seconds for each word and then moving to the next word. The RO group was asked to read the same text again without any explicit instruction. This again, was not done in the original study. This step was added in order to ensure that both groups had equal exposures to the target words.

Directly after the teaching session, three post-tests (form recall, meaning recall, and meaning recognition, respectively) were handed out. A week later, the same three tests were administered in order to gauge retention of the target words over time.

For the form recall test, accurately completed answers were given 1 , and were given 0 when completely wrong answers were provided. If the answer had only one missing/misspelled vowel/consonant, half a mark (0.5) was granted. A full point (1) was awarded for the translation test for fully correct answers (for example 'fuzzy - not clear'), and a 0 for a completely wrong answer (for example 'fuzzy - cold'). Finally, a correct answer for the MC test was given 1, while 'I don't know', wrong answers, or no answers, were scored 0. 


\section{Results and Discussions}

Since the participants were examined using the same target words and had the same number of exposures to them, it can be safely said that the results are now directly comparable to a much greater extent than they were in the Sonbul and Schmitt's (2010) study. The outcomes for the first research question: "Is explicit teaching (RE) more effective than incidental learning?" - were revealed as follows.

First, both groups started with zero knowledge of the target words, as mentioned previously. In addition, the experiment was carefully controlled in terms of ensuring that the participants were not exposed to English during the period of the pre-test and the immediate post-test other than that was given to them in the experiment. Hence, any vocabulary uptake in both groups on the immediate post-test was due to the experiment. Table 1 showed the total vocabulary gains in the three tests obtained by both groups immediately following the experiment, and one week later.

Table 1. Mean vocabulary gains under $\mathrm{RO}$ and $\mathrm{RE}$ conditions in both testing sessions $(\mathrm{N}=45)$

\begin{tabular}{|c|c|c|c|c|c|c|c|c|c|c|}
\hline \multirow[b]{3}{*}{ Session } & \multirow[b]{3}{*}{ Condition } & \multicolumn{9}{|c|}{ Type of vocabulary knowledge } \\
\hline & & \multicolumn{3}{|c|}{ Form recall (Completion) } & \multicolumn{3}{|c|}{ Meaning recall (Translation) } & \multicolumn{3}{|c|}{ Meaning recognition (MC) } \\
\hline & & $M^{\mathrm{a}}$ & $S D$ & $\%$ per cent & $M^{\mathrm{a}}$ & $S D$ & $\%$ per cent & $M^{\mathrm{a}}$ & $S D$ & $\%$ percent \\
\hline \multirow[t]{2}{*}{ Immediate } & RO & 5.88 & 2.60 & 39.2 & 4.09 & 3.71 & 27.2 & 7.23 & 3.68 & 48.2 \\
\hline & $\mathrm{RE}$ & 6.81 & 2.85 & 45.4 & 6.52 & 3.22 & 43.4 & 7.62 & 3.73 & 50.8 \\
\hline One week & RO & 3.42 & 2.22 & 22.8 & 2.42 & 2.50 & 16.1 & 6.38 & 3.54 & 37.8 \\
\hline later & $\mathrm{RE}$ & 4.70 & 2.95 & 31.3 & 5.08 & 3.50 & 33.8 & 8.00 & 3.67 & 53.3 \\
\hline
\end{tabular}

Note. a. Maximum score $=15$ words.

It can be seen that both conditions cater for vocabulary learning, however, Table 1 showed that the RO group scored well in the three tests immediately after the experiment (form recall $=39.2 \%$; meaning recall $=27.2 \%$; meaning recognition $=48.2 \%$ ), while the delayed test showed attrition in all three tests (form recall $=22.8 \%$, meaning recall, $16.1 \%$, meaning recognition $=37.8 \%$ ).

As for the RE group, Table 1 also showed that the group scored well on the three tests immediately after the experiment (form recall $=45.4 \%$; meaning recall $=43.4 \%$; meaning recognition $=50.8 \%$ ), while the delayed test also showed attrition in two tests (form recall $=31.3 \%$, meaning recall $=33.8 \%$ ), but a mild increase in the $\mathrm{MC}$ test (meaning recognition $=53.3 \%$ ).

A Mann-Whitney test in Table 2 was run to establish whether there was any significant difference between the two conditions.

Table 2. Mann-Whitney test for RO and RE groups

\begin{tabular}{ll}
\hline Mann-Whitney U & 164.000 \\
Wilcoxon W & 395.000 \\
Z & $-2.003-$ \\
Asymp. Sig. (2-tailed) & .045 \\
\hline
\end{tabular}

Table 2 above shows that the RE significantly outperformed the RO counterpart. This confirmed Sonbul and Schmitt's (2010) results with regard to the first research question. It is clear from the above results that both conditions have a strong basis for effecting vocabulary learning, although the RE seems to be much stronger. Therefore, this is in line with other researchers (e.g., Nation, 2001; Schmitt, 2008), who believe that explicit teaching is of paramount importance, especially for words with a high frequency of occurrence. Thus, the clear answer to the first research question is to confirm that explicit teaching, according to the current study, is significantly better than incidental learning.

It can be argued then that when words are met incidentally, explicit teaching can clearly draw learners' attention to certain features of the new vocabulary already encountered incidentally. Furthermore,

The second research question: "To what degree do the RO and RE input conditions facilitate vocabulary acquisition of the three levels of mastery of the form-meaning link (form recall, meaning recall, and meaning recognition)?" investigates the level of form-meaning mastery under the two learning conditions. 
The results showed that meaning recognition was the level that was best learnt (similar to that of Sonbul and Schmitt), followed by form recall, except in one case of the RE group where meaning recall came second to meaning recognition. Despite this, the general tendency conforms to Laufer, Elder, Hill, and Congdon's (2004) ranking of ease-of-learning, as can be shown below (> represents 'more learning than'; = represents 'equal learning'):

\section{Immediate post-test}

RO: Meaning recognition $>$ Form recall $>$ Meaning recall

RE: Meaning recognition $>$ Form recall $>$ Meaning recall

\section{Delayed post-test}

RO: Meaning recognition $>$ Form recall $>$ Meaning recall

RE: Meaning recognition $>$ Meaning recall $>$ Form recall

The results of the current study also support Sonbul and Schmitt's (2010) conclusion, emphasizing the idea that vocabulary learning does take the general pattern of being receptive, then proceeds to a productive level where many factors may hinder or expedite the learning process; one of these factors is the number of exposures to the target words. Therefore, teachers and learners alike should pay special attention to this in their teaching/learning process, and make sure that words are encountered many times in order to enhance vocabulary learning and consolidation.

\section{Pedagogical Implications}

The core pedagogical implication of the current study is that both incidental learning and explicit teaching assist L2 learners in increasing their vocabulary repertoire, and that both conditions are useful tools for activating different learning strategies which each condition has in common or in particular. For example, the RO group may have employed some word attack strategies that helped them discover and/or consolidate the new target words that were not possible in the explicit teaching (e.g., guessing and confirming the guesses by the extra re-reading of the passage). On the other hand, the RE group could have different word attack strategies that helped them discover and/or consolidate the target words (e.g., L1 translation).

Furthermore, reading a passage can involve deep processing of vocabulary if performed in a natural environment, free of any outside restrictions. The RO group read the passage under test conditions. Had they read it in a more comfortable way, they would have employed other strategies, e.g. highlighting new vocabulary for careful revision. Moreover, since the target words in the current study were well controlled, they only appeared once, whereas authentic texts usually provide greater opportunities for word recycling. This flexibility, unfortunately, was not present in the current study. Moreover, the expertise level of participants in this study was below intermediate which means that the guessing strategy may not have been effective for many of the participants. In addition, the goal of the reading task was not clear for either group, and this may have created a sense of carelessness on the part of the participants, as they did not see any reason for, or utility in, reading the passage. The RO group was even more disadvantaged, since they read the passage without a clear goal for the second time. This may have been boring for them. Additionally, and from a teaching point of view, the reading task is believed to develop a facility to learn some vocabulary and language aspects that were beyond the scope of the current study. In return, this leads to the assumption that the gains shown by the participants in both groups were modest.

\section{Conclusion}

It can be concluded that the current research supports the results found by Sonbul and Schmitt (2010) in that direct teaching of vocabulary leads to better gains than incidental learning, especially for the most common words. Moreover, this research can be seen as a further cycle of Sonbul and Schmitt's research that confirms their results, i.e., putting both results in a sounder stand. In addition, it can be concluded that despite the fact that direct teaching of vocabulary led to better gains than incidental learning, incidental learning also led to some positive gains that cannot be ignored. This affirms the idea that both approaches can cater for vocabulary acquisition, especially if we take into account the accumulative nature of vocabulary knowledge. Moreover, explicit teaching can be of greater benefit at some learning stages (e.g., beginning) and for certain words (e.g., the most common words), while implicit learning can lead to better results at other learning stages (e.g., advanced), and with other types of words (e.g., low-frequency words). Finally, the study echoes Sokmen's (1997) belief that the pendulum has swung to the middle where both deliberate and incidental learning are seen as a continuum, rather than as two discordant poles. 


\section{Acknowledgement}

The author would like to thank the Deanship of Scientific Research at Majmaah University for supporting this work under Project Number No. R-1441-9.

He would also like to express his deepest gratitude and appreciation to Moneera Alsalloum, the teacher in this study, who was of a great help in carrying out the experimental part of study.

\section{References}

Aebersold, J., \& Field, M. L. (1997). From Reader to Reading Teacher: Issues and Strategies for Second Language Classrooms. Cambridge: Cambridge University Press.

Alahirsh, H. (2014). Exploring the effectiveness of extensive reading on incidental vocabulary acquisition by EFL learners: an experimental case study in a Libyan University. Unpublished $\mathrm{PhD}$ thesis. University of Nottingham.

Al-Homoud, F., \& Schmitt, N. (2009). Extensive reading in a challenging environment: A comparison of extensive and intensive reading approaches in Saudi Arabia. Language Teaching Research, 13, 383-401. https://doi.org/10.1177/1362168809341508

Al-Nujaidi, A. (2003). The Relationship Between Vocabulary Size, Reading Strategies, and Reading Comprehension of EFL Learners in Saudi Arabia. Unpublished dissertation.

Alsaif, A., \& Masrai, A. (2019). Extensive reading and incidental vocabulary acquisition: the case of a predominant language classroom input. International Journal of Education and Literacy Studies, 7, 39-45. https://doi.org/10.7575/aiac.ijels.v.7n.2p.39

Bensoussan, M., \& Laufer, B. (1984). Lexical Guessing in Context in EFL Reading Comprehension. Journal of Research in Reading, 7(1), 15-32. https://doi.org/10.1111/j.1467-9817.1984.tb00252.x

Carter, R., \& McCarthy, M. (eds.), (1988). Vocabulary and Language Teaching. London: Longman.

Day, R. R., \& Bamford, J. (1998). Extensive Reading in the Second Language Classroom. Cambridge: Cambridge University Press. https://doi.org/10.1177/003368829802900211

Grabe, W., \& Stoller, F. (2002). Teaching and Researching Reading. Harlow: Longman.

Huckin, T., \& Coady, J. (1999). Incidental vocabulary acquisition in a second language. Studies in Second Language Acquisition, 21, 181-192. https://doi.org/10.1017/S0272263199002028

Krashen, S. (1993). The Power of Reading: Insights from the Research. Englewood, CO: Libraries Unlimited, Inc.

Laufer, B., Elder, C., Hill, K., \& Congdon, P. (2004). Size and strength: do we need both to measure vocabulary knowledge? Language Testing, 21(2), 202-226. https://doi.org/10.1191/0265532204lt277oa

Laufer, B., \& Sim, D. (1985). Taking the easy way out: non-use and misuse of clues in EFL reading. English Teaching Forum, 23, 7-10, 20.

Milton, J., \& Meara, P. (1995). How periods abroad affect vocabulary growth in a foreign language? ITL Review of Applied Linguistics, 107-108, 17-34. https://doi.org/10.1075/itl.107-108.02mil

Mushait, S. (2003). The Relationship of L1 Reading and L2 Language Proficiency with the L2 Reading Comprehension and Strategies of Saudi EFL University Students. Unpublished PhD thesis. Essex University: Colchester, UK.

Nagy, W. E. (1997). On the role of context in first and second language vocabulary learning. In N. Schmitt \& M. McCarthy (Eds.), Vocabulary: Description, Acquisition and Pedagogy. Cambridge: Cambridge University Press. https://doi.org/10.1017/CBO9781139858656

Nation, I. S. P. (2013). Learning vocabulary in another language. New York: Cambridge University Press.

Nation, I. S. P. (2014). What you need to know to learn a foreign language. Retrieved from http://www.victoria.ac.nz/lals/about/staff/paul-nation

Nation, I. S. P. (2015). Changing my mind about the role of the teacher in language teaching. Contact (TESL Ontario), 41(3), 36-37.

Nation, I. S. P., \& Meara, P. (2002). Vocabulary. In N. Schmitt (Ed.), An Introduction to Applied Linguistics. London: Arnold. 
Nation, I. S. P., \& Webb, S. (2011). Researching and Analyzing Vocabulary. Boston: Heinel Cengage Learning.

Nation, P., \& Newton, J. (1997). Teaching vocabulary. In M. H. Long \& J. C. Richards (Series Eds.) \& J. Coady $\&$ T. Huckin (Vol. Eds.), Second language vocabulary acquisition. The Cambridge applied linguistics series (pp. 238-254). New York: Cambridge University Press.

Paribakht, T., \& Wesche, M. (1997). Vocabulary enhancement activities and reading for meaning in second language vocabulary acquisition. In J. Coady \& T. Huckin (Eds.), Second Language Vocabulary Acquisition. Cambridge: Cambridge University Press.

Practice Reading Section. (2013). Retrieved June 18, 2013, from http://www.pearsonlongman.com/ae/marketing/sfesl/tests/grade5.html

Pellicer-Sánchez, A. (2015). Incidental learning of L2 collocations: A classroom study. Language Teaching Research. Advance online publication: DOI: 10.1177/1362168815618428.

Peters, E., \& Webb, S. (2018). INCIDENTAL VOCABULARY ACQUISITION THROUGH VIEWING L2 TELEVISION AND FACTORS THAT AFFECT LEARNING. Studies in Second Language Acquisition, 40(3), 551-577. https://doi.org/10.1017/S0272263117000407

Qian, D. (1999). Assessing the roles of depth and breadth of vocabulary knowledge in reading comprehension. Canadian Modern Language Review, 56, 282-238. https://doi.org/10.3138/cmlr.56.2.282

Read, J. (2000). Assessing Vocabulary. Cambridge: Cambridge University Press. https://doi.org/10.1017/CBO9780511732942

Rodgers, M. P. H. (2013). English Language learning through viewing television: An investigation of comprehension, incidental vocabulary acquisition, lexical coverage, attitudes, and captions (Unpublished doctoral dissertation).

Rodgers, M. P. H., \& Webb, S. (2011). Narrow viewing: The vocabulary in related television programs. TESOL Quarterly, 45, 689-717.

Rott, S. (1999). The effect of exposure frequency on intermediate language learners' incidental vocabulary acquisition and retention through reading. Studies in Second Language Acquisition, 21(4), 589-619. https://doi.org/10.1017/S0272263199004039

Sánchez, A. M., \& Schmitt, N. (2010). Incidental vocabulary acquisition from an authentic novel: Do Things Fall Apart? Reading in a Foreign Language, 22, 31-55.

Schmitt, N. (2000). Vocabulary in Language Teaching. Cambridge: Cambridge University Press.

Schmitt, N. (2008). Instructed second language vocabulary learning. Language Teaching Research, 12(3), 329363. https://doi.org/10.1177/1362168808089921

Schmitt, N. (2010). Researching vocabulary: a vocabulary research manual. Palgrave Macmillan. https://doi.org/10.1057/9780230293977

Schmitt, N. (2019). Understanding vocabulary acquisition, instruction, and assessment: A research agenda. Language Teaching, 52, 261-274. https://doi:10.1017/S0261444819000053

Sokmen, A. (1997). Current trends in teaching second language vocabulary. In N. Schmitt \& M. McCarthy (Eds.), Vocabulary: Description, Acquisition and Pedagogy. Cambridge: Cambridge University Press.

Sonbul, S., \& Schmitt, N. (2010). Direct teaching of vocabulary after reading: Is it worth the effort? ELT Journal, 64(3), 253-260. https://doi.org/10.1093/elt/ccp059

Waring, R., \& Nation, I. S. P. (2004). Second language reading and incidental vocabulary learning. Angles on the English Speaking World, 4, 97-110.

Waring, R., \& Takaki, M. (2003). At what rate do learners learn and retain new vocabulary from reading a graded reader? Reading in a Foreign Language, 15, 130-163.

Zimmerman, C. B. (1997). Do reading and interactive vocabulary instruction make a difference? An empirical study. TESOL Quarterly, 31(1), 121-140. https://doi.org/10.2307/3587978

\section{Notes}

Note 1. http://www.pearsonlongman.com/ae/marketing/sfesl/tests/grade5.html

Note 2. The teacher was an MA holder and a lecturer at the same University of the participants. 


\section{Appendix A}

\section{It's All Clear Now}

by Jean Lawler

It all started at the beginning of fifth grade. At first, Carmen wasn't really sure what was happening. In class, she had to peer to see the blackboard clearly. She had to do the same thing when she read street signs, or when she watched a movie. As the fuzziness got worse, she became more and more worried. It was important for her to see the notes and homework assignments the teacher put on the board.

It wasn't long before Carmen found herself squinting all the time, but she didn't want anyone to know that she was having a problem seeing. In class, she asked for a desk that was closer to the blackboard. One day, her teacher said, "Carmen, are you all right? I've noticed you narrowing your eyes a lot. Are you having trouble seeing the board?"

Carmen shook her head. "I'm fine, Mrs. Cruz," she said, but she knew she couldn't pretend much longer.

At home, she had to sit closer and closer to the television in order to see the picture. Her mother noticed her narrowing her eyes as she watched her favorite shows, and she began to get suspicious.

"Tomorrow I'm calling the eye doctor to set up an appointment for you," she said firmly. Carmen protested, but her mother's mind was made up.

Three days later, Carmen had new glasses and instructions from her doctor to wear them all the time. Carmen frowned in the car the whole way home.

"All of the kids at school will think I'm a nerd," she said. Her mother smiled and shook her head.

"You look just as beautiful with those glasses on as you do without them," she said. But Carmen didn't believe her.

The next day, Carmen kept the glasses in her pocket as she walked into the schoolyard. She avoided her friends and stood alone, feeling despondent.

Suddenly, she heard her friend Theresa shout.

Carmen ran over to the other girls. "What's wrong?" she asked.

"My silver ring is gone!” Theresa cried. "My sister sent it to me from California. It's very special and I can't lose it!"

Carmen could tell that Theresa was very upset. They all looked for the ring in the verdant area of the playground.

Carmen realized that she could search better if she could see better. She took the glasses out of her pocket and put them on. The objects and people around her came into sharp focus. She caught her breath. Everything looked so different! So clear! She looked down at the ground and a glimmer of silver caught her eye. It was the ring.

"Here it is," she shouted. "I've found it!" She handed it to Theresa, and Theresa slipped the ring back on her finger.

"Thanks Carmen," she said. "I never thought we'd find it." She paused. "Hey, I didn't know you wore glasses. They look great!"

Carmen had forgotten that she was wearing the new glasses. "Thanks," she replied shyly.

As they walked back toward the school building, two more girls from her class complimented her glasses. Carmen smiled. "Maybe wearing glasses won't be so bad after all," she thought.

\section{Appendix B}

\section{Target Words:}

1) peer 2) fuzzy 3) squint 4) firmly 5) protest 6) suspicious 7) frown 8) nerd 9) sharp 10) despondent 11) verdant 12) glimmer 13) shook 14) slip 15) compliment

\section{Copyrights}

Copyright for this article is retained by the author, with first publication rights granted to the journal.

This is an open-access article distributed under the terms and conditions of the Creative Commons Attribution license (http://creativecommons.org/licenses/by/4.0/). 